Int. J. Dev. Biol. 48: 397-409 (2004)

\title{
Cadherin-mediated cell-cell adhesion and tissue segregation in relation to malignancy
}

\author{
RAMSEY A. FOTY ${ }^{1}$ and MALCOLM S. STEINBERG ${ }^{*, 2}$ \\ ${ }^{1}$ Department of Surgery, UMDNJ-Robert Wood Johnson Medical School, New Brunswick, NJ, USA and \\ ${ }^{2}$ Department of Molecular Biology, Princeton University, Princeton, NJ, USA
}

\begin{abstract}
We review evidence concerning the basis for tissue segregation during embryonic development. This compartmentalization is shown to be an immiscibility phenomenon caused by changes in the strengths of adhesions between mobile cells which accompany their differentiation and generate interfacial tensions at cell population boundaries. The mobile cells exchange neighbors in response to these adhesion-generated forces which impel the system toward the configuration of maximal binding. Cadherins dominate these intercellular adhesions, but integrin-fibronectinbased adhesions also contribute to them as well as to cell-matrix adhesions. At the interface between two segregating cell populations are three kinds of cell-cell interfaces: $a-a, b-b$ and $a-b$. Tissue immiscibility (segregation) results when the cross-adhesion is weaker than the mean value of the two kinds of self-adhesions, does not require (although it permits) qualitative changes in cell adhesion molecules and is easily generated even by moderate changes in the quantities of adhesion molecules on the cell surfaces. All type I and II cadherins tested cross-adhere, in most cases with strengths close to those of their self-adhesions. Is malignant invasion a process of cell segregation in reverse, in which the cross-adhesion between cancer cells and host tissue components is strong relative to their self-adhesions? We review evidence for cadherin involvement in breast, prostate and brain cancers. Despite evidence that $\mathrm{N}$-cadherin enhances the invasiveness of certain cancer cells, we have found that increasing the expression not only of functional E-cadherin but also of $P$ or $\mathrm{N}$-cadherin restrains the spreading of other malignant cell lines over (and through) a reconstituted extracellular matrix.
\end{abstract}

KEY WORDS: cadherin, integrin, segregation, sorting-out, invasion

\section{Introduction}

The establishment and maintenance of boundaries and compartments between cell populations is essential to morphogenesis. This process is inherently a physical one but it has molecular roots traceable largely to the activities of adhesion systems mediating both cell-cell cohesion and cell-substratum adhesion. These cell adhesion systems include cadherins, integrins and ECM proteins, the last of which are subject to remodeling by degrading enzymes such as matrix metalloproteinases (MMPs) and their tissue inhibitors (TIMPs). These components are also involved in the transition of benign, organ-confined tumors to invasive and lethal malignancies. The transition to malignancy is accompanied by a de-assembly process resulting in the elimination of boundaries and compartments. From a physical perspective, tissue segregation may be viewed largely as an immiscibility phenomenon between cells undergoing differentiation, whereas invasion more closely re- sembles a process of evolving miscibility between de-differentiating tumor cells and the tissues they invade. Whether tumor cells segregate or intermix depends in part on a balance between the forces binding cells together and those promoting interaction of tumor cells with various components of the microenvironment in which they reside. Direct cell-cell adhesions have usually been attributed in large measure to homophilic interactions between cadherins, whereas cell-ECM association has been largely attributed to the heterophilic interaction of integrins with the ECM. Recently, however, demonstrations that integrin-fibronectin (FN) interaction can generate strong intercellular adhesions (Robinson

Abbreviations used in this paper: DAH, Differential Adhesion Hypothesis; DITH, Differential Interfacial Tension Hypothesis; EC, ectodomain; ECM, extracellular matrix; FN, fibronectin; LLC, Lewis lung carcinoma; MMP, matrix metalloproteinase; $\sigma$, surface tension; TIMP, tissue inhibitor of metalloproteinase; TMA, tissue microarray.

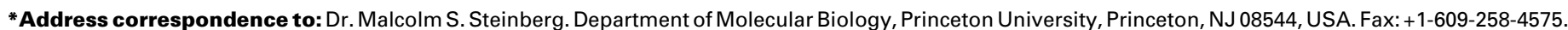
e-mail: msteinberg@molbio.princeton.edu
} 
et al., 2004, Robinson et al., 2003) and that cross-talk between cadherins and integrins influences their respective functions (von Schlippe et al., 2000) have blurred the roles of these two major adhesion systems. This review will summarize recent advances contributing to our understanding of the processes of adhesionmediated tissue segregation and invasion. We will focus on the contribution of cadherins and integrins to these processes. Our goals here are to highlight how the interplay between genetic information, the molecular machinery it encodes and principles of physics influences the self-assembly processes so essential to morphogenesis and to explore the extent to which an understanding of these processes can give insights into the intermixing of tumor and stromal cells observed during malignant invasion.

\section{Cadherins}

Cadherins are a large family of calcium-dependent, transmembrane adhesion molecules with a broad range of functions including direct cell-cell cohesion (Bogenrieder and Herlyn 2003, PerezMoreno et al., 2003), inhibition of apoptosis (Alahari et al., 2002) and cell signaling (Perez-Moreno et al., 2003, Yap and Kovacs 2003). The cadherins form a superfamily with at least six subfamilies, which can be distinguished on the basis of protein domain composition, genomic structure and phylogenetic analysis of the protein sequences. These subfamilies comprise classical or typeI cadherins, atypical or type-II cadherins, desmocollins, desmogleins, protocadherins and Flamingo cadherins. Classic cadherins all contain five cadherin ectodomains (EC's) of approximately 110 residues each. EC1-4 are all closely homologous while EC5 is less well conserved. All cadherins, except T-cadherin, contain a catenin-binding domain. Classical cadherins mediate homophilic adhesion between cells in a $\mathrm{Ca}^{2+}$-dependent manner. Type I cadherins contain a conserved HAV sequence in their EC1 domains. Type II cadherins lack this motif. Type 1 cadherins include E, N, P, R, B, K, C, XB, EP and the Drosophila DE and DN cadherins. Type 2 cadherins include VE-, OB, $F$ and cadherins 6 , $7,8,10,11,12$, among others.

\section{Tissue segregation during embryogenesis}

During vertebrate embryonic development, contiguous sheets of tissue are progressively parsed out into the various organ primordia. Beginning with the first morphogenetic movements, the primary germ layers - ectoderm, mesoderm and endoderm separate out. The ectoderm then becomes subdivided to form epidermis, neural plate and neural crest. The mesoderm becomes partitioned into notochord, somites and lateroventral mesoderm, following which the somites are further partitioned into dermatome, myotome and sclerotome, from which are formed dermis, skeletal muscle and vertebral skeleton; and so on. Once tissue segregation has occurred (compartmentalization), tissues representing different compartments actively maintain these boundaries and reestablish them when they are disturbed. This is illustrated by two kinds of tissue behavior demonstrable experimentally: the behavior of tissue fragments placed in apposition and that of their experimentally intermixed cells (Steinberg 1998, Steinberg 2003). When two embryonic tissue fragments are placed in contact in culture medium, they will merge and their boundary will be effaced if the fragments are identical in kind. If the fragments come from tissues that have already begun to segregate in the embryo, however, their behavior is entirely different: the boundary between them will be maintained and one member of the pair will typically begin to spread over the surface of the other. This was first shown in the classical experiments of Johannes Holtfreter with amphibian embryonic tissues. He referred to these tendencies of embryonic tissues to associate with one another as "tissue affinities" (Holtfreter 1939).

\section{The sorting-out of experimentally intermixed embry- onic cells}

When embryonic tissue fragments like those described above are dissociated into single cell suspensions and these are reaggregated to form individual mixed aggregates, they will remain intermixed if the tissues of origin were identical in kind. However, if the cells have come from tissues that had already begun to segregate in the embryo, their behavior again is entirely different: they engage in a process of "sorting-out" in which, if their relative numbers permit, one cell population typically coalesces to form discrete islands within a sea comprised of the other cell population (Holtfreter 1939, Steinberg 1962a, Steinberg 1962b, Steinberg 1962c, Steinberg 1963, Steinberg 1964, Steinberg 1970, Townes and Holtfreter 1955).

\section{Liquid-like behavior of embryonic cell populations}

In our analysis of these behaviors, we pointed out that they accurately mimic behaviors that are well known and understood in the inanimate world: the spreading of one liquid over the surface of another and the "breaking" of a dispersion or emulsion of two immiscible liquids. If confronted as a pair of droplets, a spreading oil (of lower surface tension) spreads over the surface of water, while if the oil and water are codispersed in a single droplet, the dispersion "breaks" or sorts out, the oil again coming to occupy the external surface. The determinants of this behavior in liquids are their relative surface and interfacial tensions, which are global reflections of the intensities of cohesion and adhesion between their component subunits (Rowlinson and Widom 1989). For a system to show such behavior it must (1) be composed of many subunits which (2) cohere while (3) being mobile. These are the defining characteristics of a liquid. In ordinary liquids the subunits are molecules and the mobility is Brownian. The rearranging cell populations we have been discussing also possess these same three properties that underlie liquid behavior but their subunits are living cells whose mobility may be either active, driven by intracellular forces, or passive, pulled by external forces (Armstrong and Parenti 1972, Steinberg and Wiseman 1972). We proposed that, by analogy with inanimate immiscible liquids whose rearrangements are driven by intermolecular attractions that act to maximize global binding energy, these rearrangements of cells are guided by intercellular adhesions acting to do the same (Steinberg 1962a, Steinberg 1962b, Steinberg 1962c, Steinberg 1963, Steinberg 1964). We called this the "Differential Adhesion Hypothesis" (DAH) (Steinberg 1970) and demonstrated that the liquidlike behaviors displayed by such cell populations extended well beyond those already described. For example, the DAH explained why irregularly shaped tissue 
fragments commonly round up toward a spherical shape (maximizing intercellular adhesion). It also explained why apposed tissue fragments spreading, one over the other and their dissociated, intermixed and coaggregated individual cells, following entirely different pathways (tissue spreading vs. cell sorting), approach the same final anatomical configuration (both advance toward that configuration which maximizes global binding energy).

This hypothesis led to another unique prediction. Unlike an earlier concept that viewed cell sorting as an expression of homotypic preference for "self" ("like prefers like"), reviewed in (Steinberg 1978b), the DAH predicted that the configurations arrived at after a group of tissue samples are combined in all possible pairs should reveal the operation of a strict rule of transitivity. One tissue - the one of lowest cohesivity (surface tension) - should tend to spread upon each of the others; a second tissue - the one of next higher cohesivity - should tend to spread upon each of the remaining tissues; and so forth, the tissue of greatest cohesivity tending to be spread upon by all of the others. This should occur because any liquid tends to spread over any other liquid of greater surface tension. This prediction was tested, in experiments that took over seven years to complete, by mixing and coaggregating the dissociated cells of six different chick embryonic tissues in all fifteen possible binary combinations and by combining five of the six as paired tissue fragments in all ten possible binary combinations. The large number of combinations was dictated by the desire to reduce to about the $2 \%$ level the probability that a hierarchy would arise fortuitously through chance alone. A perfect spreading hierarchy was indeed revealed (Steinberg 1970). The entire syndrome of liquid-like behaviors of embryonic cell aggregates documented by these experiments is shown in Fig. 1.

\section{Tissue surface tensions $(\sigma)$ : a physical test of the DAH}

Up to this point the only available experimental strategy for testing the DAH was that of comparing cell population behaviors predicted by the $\mathrm{DAH}$ or by competing hypotheses with those revealed by experiments designed to examine them. The demonstration that the relative positions of tissues paired in binary combinations define an inside/outside hierarchy opened up the possibility of a direct physical test of the DAH, which predicted that this hierarchy should rank the tissues according to the magnitudes of their surface tensions. However, until that time, surface tensions of fluid tissues had never been conceived of, much less measured. Fortunately, Herbert Phillips, a recently arrived graduate student with a background in physics, pointed out that the relevant thermodynamics required this to be done through measurements of the shapes of liquidlike cell aggregates at shape equilibrium under a measured distorting force. The effort to make such measurements became the focus of Phillips' PhD thesis (Phillips 1969, Steinberg 2003). Initially a sustained deforming force was applied to living embryonic cell aggregates in a specially adapted incubatorcentrifuge (sessile droplet method) (Phillips 1969, Phillips and Steinberg 1969). Phillips and his student, Grayson Davis, subsequently applied sustained deforming forces to spheroidal cell aggregates of amphibian gastrula tissues by compressing them between parallel plates to which they did not adhere, calculating the tissue surface tensions from the Young-Laplace equation (Davis 1984, Phillips and Davis 1978). These experiments were later extended, demonstrating that Holtfreter's "tissue affinities" governing germ layer flow during early stages of amphibian development are reflected in tissue surface tensions (Davis et al., 1997). We subsequently devised a parallel plate tissue surface tensiometer which continuously records both the force applied to a living cell aggregate and the aggregate's profile shape, allowing the approach to shape equilibrium to be constantly monitored in real time. Using this apparatus, we reported numerical surface tension values for chick embryonic tissues which correspond precisely with the hierarchy in these tissues' mutual envelopment preferences (Foty et al., 1994, Foty et al., 1996). The probability that this correspondence was fortuitous being 0.0083 , these measure-
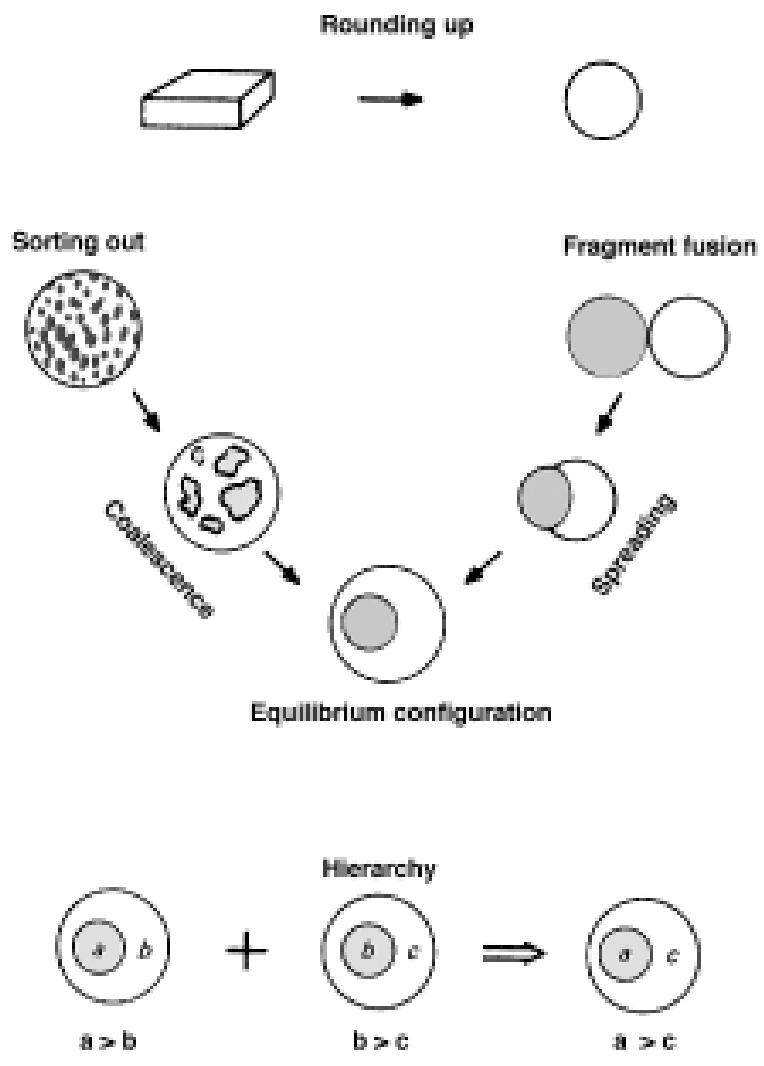

Fig. 1. Syndrome of behaviors displayed both by many embryonic cell populations and by ordinary liquids or immiscible liquid pairs. (Top) A mass of arbitrary shape rounds up to form a sphere, minimizing its surface area. (Middle) Intermixed phases sort out by a process of coalescence, forming a continuous externalizing phase which envelops, to a greater or lesser degree, a discontinuous, internalizing phase. When touched together as separate masses, the same two phases spread, one over the other, to approach the same (equilibrium) configuration approached by sorting-out. (Bottom) In a set of mutually immiscible phases, the tendencies of one phase to spread over another are transitive; i.e., if $b$ tends to spread over a and $c$ tends to spread over $b$, then $c$ will tend to spread over a. From (Phillips 1969, Phillips and Davis 1978). 
ments demonstrated that the syndrome of liquidlike behavior of embryonic tissues illustrated in Fig. 1 does indeed result from the tissues' relative surface and interfacial tensions.

\section{Do tissue $\sigma$ 's arise from differential adhesion or cell surface contraction?}

How are these tissue surface and interfacial tensions generated? The DAH proposed that they derive directly from the binding energies between and among a tissue or cell aggregate's component cells just as the surface and interfacial tensions of inanimate liquids derive directly from the association energies between and among their component molecules. However, an alternative source has been proposed. Harris (Harris 1975) presented a number of alternative hypotheses, among which his preference was for the "differential surface contraction hypothesis", which holds that "The more strongly contractile a given cell type is over its exposed surface, the more internally it should sort out relative to other, less contractile cell types." Recently, Brodland has revived this proposal with his "differential interfacial tension hypothesis (DITH)." He writes (Brodland 2002), "The basic tenets of the DITH are that net or equivalent surface tensions arise along the edges of cells" (emphases ours) and that "cell type specific differences in the values of these tensions give rise to local displacements of triple junctions" (between cells) "which ultimately lead to specific patterns of cell rearrangement." Both the Harris and Brodland versions of this hypothesis derive tissue surface tensions not from the strengths of cell-cell adhesions but rather from contractile forces associated with the surface regions of individual cells.

Brodland notes that "it is important that ... special attention (be) given to distinguishing between the mechanical effects of interfacial tensions and those of cell-cell adhesions" and laments that "Unfortunately, experiments with cells that have been engineered to produce specific interfacial tensions are not yet available." However, a decision favoring either a cell surface contraction hypothesis or the DAH could be made if either cell surface contractility or cell-cell adhesiveness could be experimentally
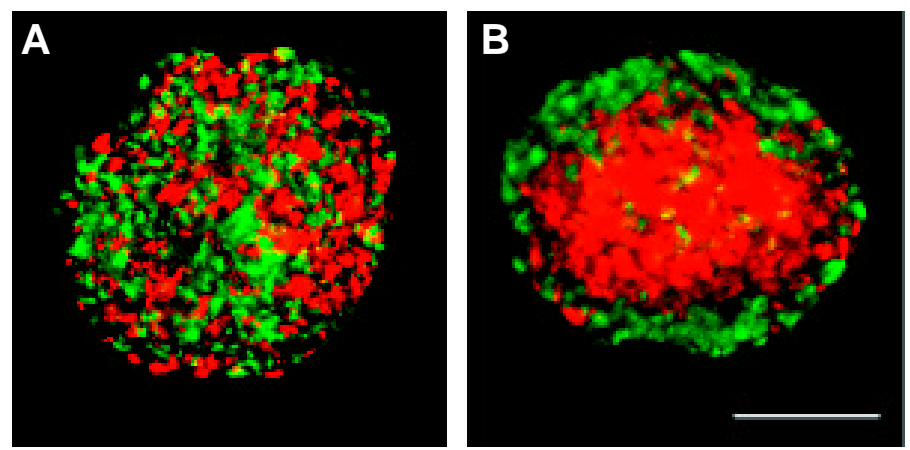

Fig. 2. Sorting-out of cells expressing the same cadherin. Equal numbers of red and green cells were intermixed and pelleted by centrifugation, then cut into fragments and cultured in suspension overnight to allow the aggregates to reorganize. (A) An aggregate containing a mixture of red-and green-labeled $L$ cells of the same $N$-cadherin-expressing cell line rounded up, the cells remaining intermixed. (B) $L$ cells (red) expressing a $50 \%$ higher level of $N$-cad segregate internally to $L$ cells (green) expressing the same cadherin at a lower level. Confocal image. Scale bar represents $100 \mu \mathrm{m}$. From (Duguay et al., 2003). varied independently of the other parameter. While differential cell surface contractility can not easily be manipulated quantitatively, differential cell-cell adhesiveness can be. Indeed, such an experiment had been reported eight years earlier. In that experiment, we transfected $L$ cells, which initially express no cadherins and do not aggregate, to express P-cadherin at two substantially different levels. The cells then became mutually adhesive and formed aggregates. These two cell populations were then combined both as apposed aggregates and as intermixed cells. Tissue spreading or cell sorting proceeded exactly as has been described above, the cell population expressing P-cadherin at the lower level coming to envelop the higher-expression population (Steinberg and Takeichi 1994).

We went on to investigate how small a difference in cadherin expression levels is sufficient to produce these morphogenetic consequences. Two L-cell lines expressing surface $\mathrm{N}$-cadherin molecules in a ratio of about 3:2 were stained to fluoresce red or green, mixed in equal numbers and coaggregated. Fig. $2 \mathrm{~A}$ is a confocal section through the center of an aggregate, cultured for a day, in which both the red- and the green-labeled cells express $\mathrm{N}$ cadherin at the same level. The two cell populations did not segregate. Fig. $2 \mathrm{~B}$ is a confocal section through the center of a similarly prepared aggregate containing a mixture of the cells expressing $\mathrm{N}$-cadherin in higher (red) and lower (green) amounts. The $50 \%$ difference in mean $\mathrm{N}$-cadherin surface expression level between these two lines was sufficient to cause them to segregate from one another during one day of culture, with the lowerexpressing (green) cells completely enveloping the higher-expressing (red) cells (Duguay et al., 2003). As in our earlier experiments with chick embryonic cells, lower cohesion causes external positioning. The surface tensions of aggregates of these two cell lines were measured and found to be directly proportional to the cadherin expression levels of their component cells. In preliminary experiments, even a $26 \%$ difference in mean cadherin expression level has been sufficient to produce a degree of cell sorting in mixed aggregates cultured for two days (A. Flagg, undergraduate thesis). These two cell lines being subclones of the same parent line, the only difference between them is the level of cadherin expression. These experiments demonstrate that the surface tensions of these cell lines are generated by interactions of the adhesion molecules expressed in their surfaces and, the cells being identical in all other respects, not by differences in the contractility of their surfaces. We believe that these experiments represent the final proof of the $\mathrm{DAH}$.

\section{Most-stable configurations of heterogeneous, liquid- like cell populations}

The surface and interfacial tensions of binary liquid systems specify more than the liquids' miscibility or immiscibility. Since these thermodynamic parameters impel rearrangements that bring the system ever closer to that configuration in which its interfacial free energy is minimized (i.e. its inter-subunit bonding energy is maximized), they specify the precise configuration that any liquid system will approach. This applies to all systems that display the syndrome of behavior shown in Fig. 1, including multicellular systems. Two examples of such "equilibrium configurations" - that of a sphere and that of a sphere within a sphere - are shown in Fig. 1. These and other examples of possible equilibrium configurations are shown in Fig. 3, together with the intercellular adhesive 
relationships that engender them. For the purpose of this illustration, which considers only the simplest case, in which each cell's adhesive properties are uniform on all sides, these adhesive relationships are expressed here not as $\sigma$ 's but as the reversible works of cohesion and adhesion (Ws) derived from them (Davies and Rideal 1961) according to the relationships

$$
\begin{gathered}
\mathrm{W}_{a}=2 \sigma_{a o} \\
\mathrm{~W}_{b}=2 \sigma_{b o} \\
\mathrm{~W}_{a b}=\sigma_{a o}+\sigma_{b o}-\sigma_{a b}
\end{gathered}
$$

where $\mathrm{W}_{a}$ represents the cohesivity of the more cohesive phase $a$ in medium $0, W_{b}$ represents the cohesivity of the less cohesive phase $b$ in medium $o$ and $W_{a b}$ represents the adhesivity of phase $a$ to phase $b$. Ws are used here because each $W$ reflects the intensity of one species of adhesive interface (either $a$ - $a, b-b$ or $a$ $b$ ), corresponding to one's intuitive sense of cohesivity, whereas $\sigma_{a b}$ is a function of $a-a$ and $b$ - $b$ as well as $a-b$ adhesive intensities. As shown in this figure (in which the vertical axis shows the relative binding intensities of each of the species of interface) and as is intuitively obvious, if cohesive cell populations $a$ and $b$ have no adhesion to each other, the combined phases will form separate, detached spheres (Case D: near-analog, fluorocarbon oil and water). A positive but relatively low degree of "cross-adhesion" weaker than either of the "self-adhesions" - produces a configura-

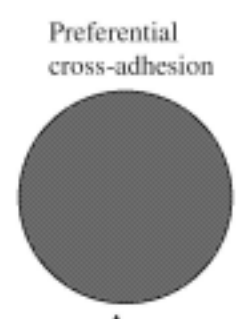

$\mathbf{A}$

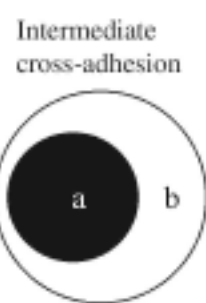

B

\section{Relatively weak} cross-adhesion

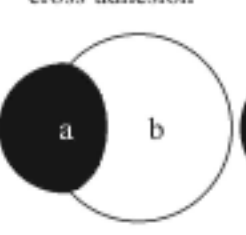

$\mathrm{C}$
No

cross-adhesion

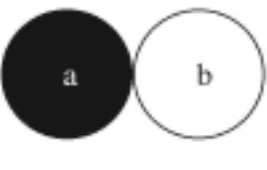

D

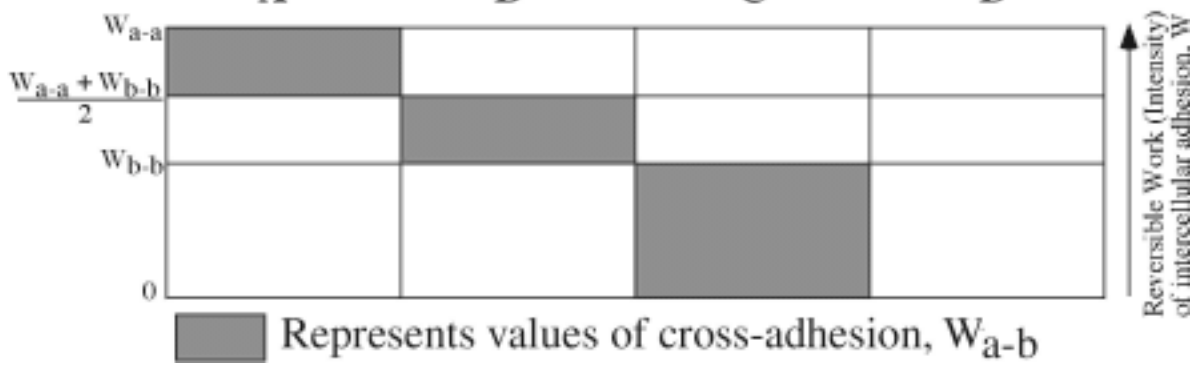

Fig. 3. Illustration of how the reversible works of cohesion $\left(W_{a-a}\right.$ and $\left.W_{b-b}\right)$ and adhesion $\left(\mathbf{W}_{\mathrm{a}-\mathrm{b}}\right)$ determine the most stable configuration of a liquid system. These relationships should apply to any multi-subunit system which adopts liquid-like equilibrium shapes, whether the subunits are molecules or cells. The figure depicts, for a two-phase liquid system, the equilibrium configurations determined by different sets of Ws. By convention, when the two phases differ in cohesiveness, the more cohesive phase is designated a and the less cohesive phase is designated $b$. In the figure, $W_{a-a}$ and $W_{b-b}$ are represented as having higher and lower arbitrary values represented by horizontal solid lines. The figure is divided into four vertical areas, the shading representing a range of values of $W_{a-b}$ from infinity (column $\mathbf{A}$ ) to zero (column $\mathbf{D}$ ). A high value of $W_{a-b}$ (higher than the mean of $W_{a-a}$ and $W_{b-b}$ ) causes the two phases to mix preferentially (column A). Zero adhesion between a and b subunits (column D) causes phases $a$ and $b$ to round up into separate, isolated spheres. Low but positive values of $W_{a-b}$ (between 0 and $W_{b-b}$ ) lead to a partial envelopment of phase a by phase $b$ (column $\mathbf{C}$ ), while higher values of $W_{a-b}$ (above $W_{b-b}$ but below the average of $W_{a-a}$ and $W_{b-b}$ ) lead to complete envelopment of phase a by phase b (column B). After (Steinberg 1978a). tion in which the less cohesive cell population $b$ partiallyenvelops the more cohesive population $a$ when total binding energy is (Case C; analog, mineral oil and water). If the two cell cross-adhere with an intensity equal to or greater than mized (Case B: analog, oleic acid and water). Finally, if the two cell populations cross-adhere with an intensity equal to or greater than the average of the intensities of the two populations' self-adhe-

\section{How subtype-specific are cadherin-mediated cell-cell}

The generation of different tissue arrangements by the actions of different sets of relative intercellular binding energies provides anatomical window into the relative binding energies among the populations' measured surfacetensions (self-adhesions) and their utual envelopment tendencies (Davis et al., 1997, Duguay et al., Foty et al., 1994, Foty et al., 1996). However, there exists a present no way to make direct physical measurements of cell populations' interfacia/tensions (cross-adhesions). The best that can be done is to draw deductions about this from the configurations that combinations of cell populations adopt. The results are extremely interesting, contravening a widespread belief in the general subtype-specificity of interactions between different cadherin family members. If different cadherins could not cross-adhere, then otherwise non-cohesive cells transfected to express them should not cross-aggregate but should form separate spheres (Fig. 3, Case D). If different cadherins do cross-adhere, but more weakly than identical cadherins, then otherwise non-cohesive cells transfected to express them should cross-aggregate but go on to adopt a configuration of partial envelopment of one cell population by the other (Fig. 3, Case C). If the cross-adhesions are at least as strong as those between the less cohesive of the two cell populations but not as strong as the average of the two cell populations' individual cohesivities, the less cohesive cell population should envelop its partner completely (Fig. 3, Case B). Finally, if the cross-adhesions are as strong as or stronger than this average value, the two cell populations should intermix (Fig. 3, Case A). It is instructive to compare these expectations with the aggregative behavior displayed and the configurations actually adopted by such combinations of cadherin-expressing cells.

We have paired $L$ cell populations transfected to express each of eight different type I 

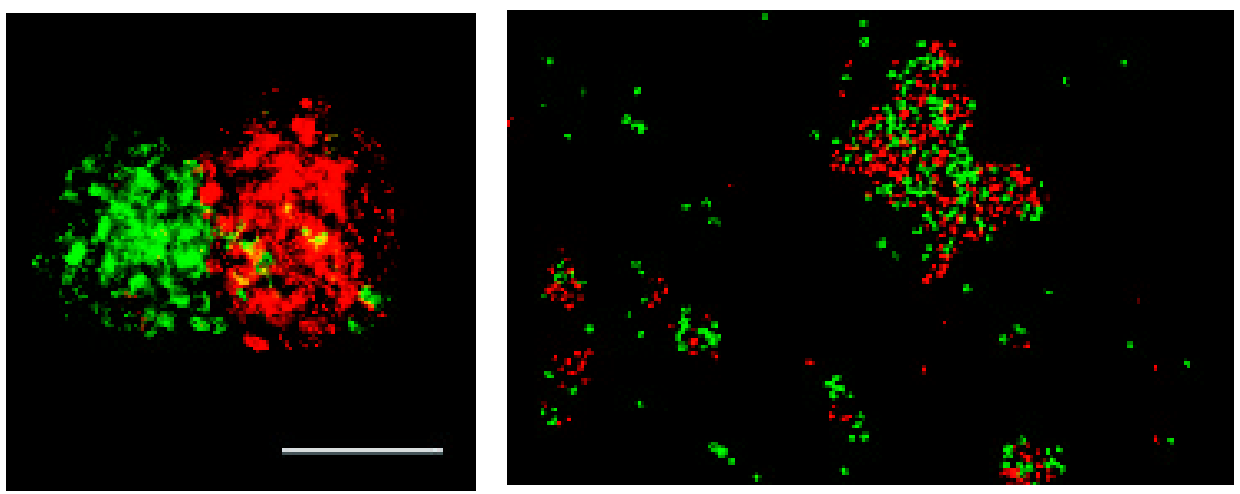

Fig. 4 (Left). Heterocadherin-mediated cell sorting. Aggregates containing equal numbers of L cells expressing B-cad (green) and R-cad (red) segregated to produce mounds of $R$-cad-expressing cells partially capping a B-cad-expressing mass. Confocal images. Scale bar represents $100 \mu$ m. From Duguay et al. (2003).

Fig. 5 (Right). Cross-adhesion between cells expressing different type I cadherins. L cells expressing P-cad (red) vs. E-cad (green) coaggregated under moderate shear conditions. From Duguay et al. (2003).

and type II classical cadherins and examined both their aggregative behavior and the configurations adopted after cell rearrangement (Duguay et al., 2003 and in preparation). In no case were the paired cell populations incapable of cross-aggregation, even when cells expressing type I vs. type Il cadherins were combined, although cross-aggregation could in some combinations be inhibited by sufficiently high shear forces. This means that in some combinations, in the instant of collision between cells in a sheared suspension, "heterocadherin" adhesions (between different cadherins) are made more slowly than "homocadherin" adhesions (between identical cadherins). In a few cadherin combinations, the configuration adopted after cell rearrangement was one of partial envelopment (Fig. 3, Case C; Fig. 4), indicating that cellcell adhesions mediated by these particular cadherin pairs are indeed weaker than their respective self-adhesions. In the great majority of cadherin combinations, however, the configuration adopted after cell rearrangement was one of complete envelopment (Fig. 3, Case B), implying that the more weakly cohesive cell population adhered to its partner no less strongly than to itself. Since this is the configuration adopted by cell populations differing only in the amount of a given cadherin expressed at their surfaces (Steinberg and Takeichi 1994) (Fig. 2), we considered the possibility that in such cases homocadherin and heterocadherin adhesions may be of equal binding energy. To examine this possibility, we combined $L$ cells transfected to express at their surfaces either $\mathrm{P}$-cadherin or E-cadherin at measured levels. This is the combination of cadherin-expressing cells whose initially separate aggregation in sheared cell suspensions formed the basis of the first report of adhesive specificity among cadherin subtypes (Nose et al., 1988). In our hands, L cells expressing Ecadherin vs. P-cadherin readily co-aggregated (Fig. 5). L cells expressing more $\mathrm{P}$ - cadherin than $\mathrm{E}$ - cadherin sorted out with the former completely enveloped by the latter (Fig. 6A). $L$ cells expressing less $\mathrm{P}$ - cadherin than $\mathrm{E}$ - cadherin sorted out in the reverse configuration, with the latter completely enveloped by the former (Fig. 6C). Both results are consistent with the principle that more cohesive cells segregate internally to less cohesive ones. When $\mathrm{P}$-cadherin and $\mathrm{E}$-cadherin expression levels were closely matched, however, the two cell lines did not sort out (Fig. 6B). Two conclusions follow. First, E- cadherin and P- cadherin must produce about equal adhesiveness on a molar basis, a conclusion supported by direct measurements (Foty et al., in preparation). Moreover, these two cadherins must also cross-adhere with an intensity similar to that with which each self-adheres, as evidenced both by the complete envelopment displayed in Figs. 6A and $\mathrm{C}$ and by the failure of cells expressing these different

Fig. 6. $L$ cells expressing $E-$ vs. Pcad sort out only when they differ in cadherin expression level. $L$ cells expressing P-cad (red) or E-cad (green) were co-pelleted and formed a coherent aggregate. This was then cut into small pieces that were cultured in suspension for two days. In (A), the E-cad-expressing cell line E8a, paired with cell line $L P 1$, expressing $P$-cad at a higher level (Table 1), segregated externally. In (B) and $(C)$, inducible E-cad-expressing cell line LE-
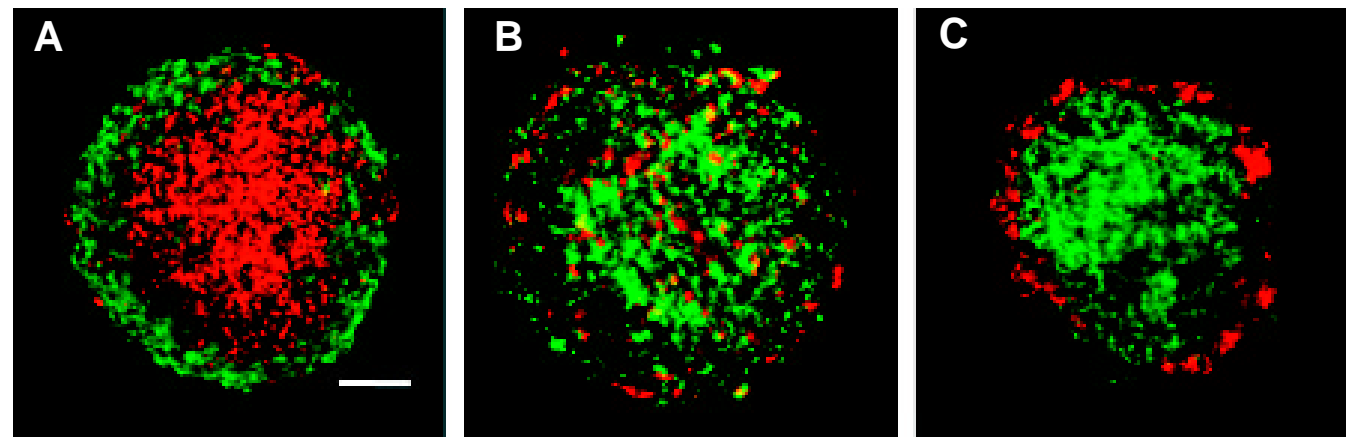

Dex was used. (B) E-cad expression was approximated to that of the P-cad line and no sorting-out occurred. (C) The E-cad-expressing line LE-Dex was induced to an expression level greater than that of the P-cad-expressing line LP1 and segregated internally. Confocal images. Scale bar represents100 $\mu \mathrm{m}$. From Duguay et al. (2003). 
cadherins at the same level to sort out. The sorting-out of cell populations exclusively expressing these two cadherins must therefore be entirely due to quantitative differences in their expression and not at all to cadherin subtype specificity (Duguay et al., 2003).

\section{Tissue segregation: of theories and measurements}

Few subjects within the fields of cell and developmental biology have been so riven with misunderstanding and disagreement as that dealing with the sorting-out of embryonic cells. One of us has written extensively about this (Duguay etal., 2003, Moyer and Steinberg 1976, Steinberg 1970, Steinberg 1975, Steinberg 1978b, Steinberg 1996) but here we wish only to note what we regard as the underlying causes. The DAH arose from the first experiments designed to discriminate among three competing explanations for the reorganizational behavior Holtfreter categorized under the rubric of "tissue affinities" (Holtfreter 1939, Townes and Holtfreter 1955). The results of these experiments were inconsistent with the other two explanations but in perfect accord with the predictions of the DAH. Already in these first papers, attention was called to the liquidlike nature of these rearrangements and tissue surface tensions arising from differential intercellular adhesive intensities were proposed to underlie them (Steinberg 1962a, Steinberg 1962b, Steinberg 1962c, Steinberg 1963, Steinberg 1964, Steinberg 1970).

The first effort to measure these postulated differential intercellular adhesive intensities (Roth 1968, Roth and Weston 1967) measured not intercellular binding intensities but rather the rates of adhesion of marked cells to cell aggregates of like and unlike kind in sheared suspensions. This measurement of binding rates with the intention to quantify binding energies was physically unsupportable (Moyer and Steinberg 1976, Steinberg 1970). Nevertheless, it found favor among cell and developmental biologists little engaged with physics but thoroughly steeped in the biochemical specificities of antigen-antibody and enzyme-substrate reactions because the cells were found to bind to aggregates of like cells faster than to those of unlike cells. This fitted in with the popular paradigm that the sorting-out of embryonic cells within mixed reaggregates represents a phenomenon of selfrecognition - "like prefers like" - promoted since the 1950s by Moscona and his associates who claimed to have discovered tissue-specific cell aggregation "factors" released by cells into the medium. This claim vanished with the discovery of actual cell adhesion molecules (reviewed in (Steinberg 1996)), but the belief that the segregation of intermixed cells within a common aggregate implies that the segregating cells must utilize incompatible adhesion systems remained. After the discovery of the family of cadherins and the demonstrations (1) that cadherin-mediated adhesion is "homophilic" ("like prefers like") and (2) that different tissues may display different cadherins (reviewed in (Takeichi 1995)), these adhesion molecules seemed like plausible candidates for the expected molecular mediators of tissue-specific cell adhesion. The dramatic finding that the initiation of a morphogenetic movement such as gastrulation or neurulation is usually marked by a change in cadherin subtype (Takeichi 1988) fitted perfectly into this picture, which seemed to be confirmed when Eand $P$-cadherin-expressing $L$ cells were mixed in a sheared suspension and found to aggregate separately (Nose et al., 1988).

Again, the use of sheared cell suspensions to assess cells' adhesive capacities produced misleading results related to those reported by Roth and Weston twenty years earlier. Such assays cannot reflect the binding energies or strengths of physiological, cadherin-mediated adhesions not only for the reason cited above but also because physiological adhesions are greatly strengthened by interactions among and between cadherins, catenins, other cytoskeletal proteins and actin that occur only after the initiation of adhesions, during the course of the following hour or so (Adams et al., 1996, Angres et al., 1996). During shearmediated aggregation, a colliding cell pair has only a second or so to develop enough binding energy to resist re-separation (Duguay et al., 2003). The shear forces used to produce cell aggregation in stirred systems produce the analog of an activation energy barrier to aggregation (Steinberg 1970) which can be raised or lowered by adjusting the shear rate. Thus, stirring a heterogeneous cell suspension may permit the formation of certain rapidly formed adhesions while preventing the formation of other adhesions that form more slowly, giving a false impression of intrinsic adhesive selectivity. A failure to form "heterotypic" aggregates in such a circumstance provides no evidence of the ability of the differing cells to adhere, even strongly, in the absence of shearing (Duguay et al., 2003). Moreover, the finding that cell populations utilizing identical adhesion molecules expressed in moderately differing amounts sort out, one population enveloping the other, disproves the belief that sorting-out requires a low degree of recognition between the two cell populations' adhesion systems.

Lessons we hope will be drawn from these facts by future investigators are that the aggregation rates of sheared cell suspensions cannot be used to evaluate the strengths of cell-cell adhesions but that measurements rooted in thermodynamics can; and that neither cell segregation in mixed aggregates nor the separate aggregation of different kinds of cells mixed together in sheared suspensions demonstrates adhesive selectivity at the
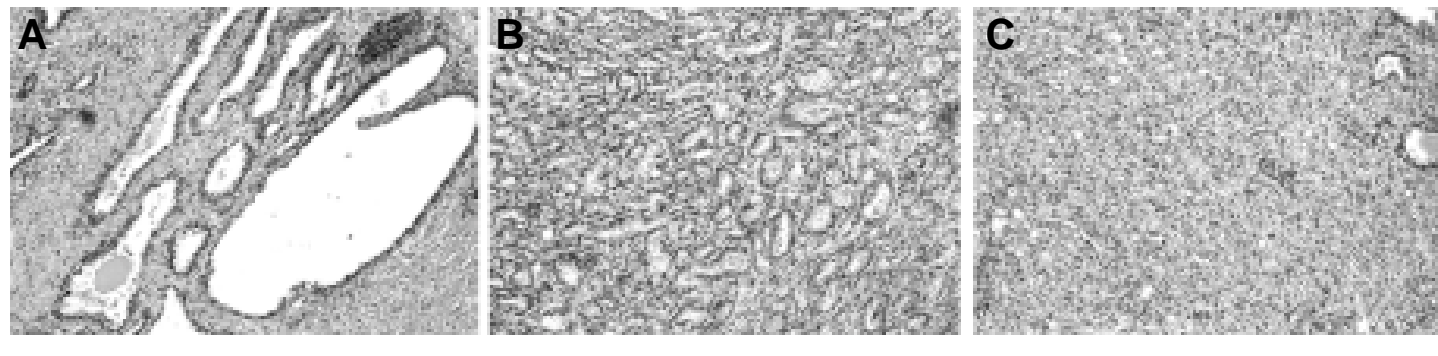

Fig. 7. Histological progression of prostate cancer. (A) Normal prostate gland. (B) Gleason grade 3 (low grade) prostate cancer. (C) Gleason grade 5 (high grade) prostate cancer. Note progressive loss of compartmentalization as normal prostate glands progress through malignancy. 

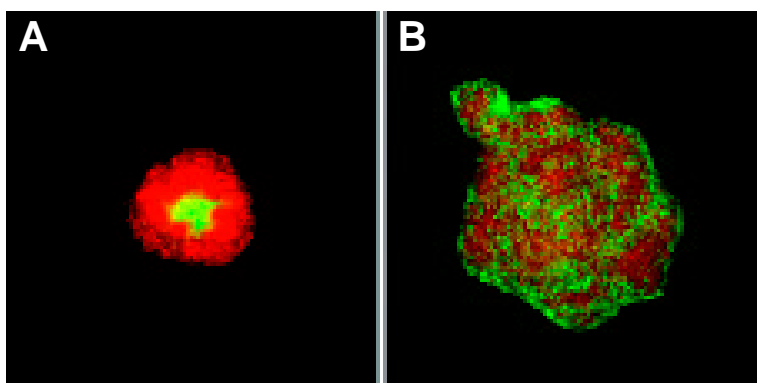

Fig. 8. Cell sorting in prostate cancer. Sorting of the non-invasive Dunning rat prostate cancer AT-2 cell line and normal Rat 2 fibroblast cells over 24 hours (A) in hanging drop cultures as compared to sorting of highly invasive MLL and Rat 2 cells over the same time periods (B). Note that AT2 and Rat 2 cells sort out into two separate phases over a 24-hour period, with the Rat 2 cells occupying the internal position (A). This is in sharp contrast to MLL and Rat 2 cells which remain intermixed over the same time period $(B)$

molecular level but that the configurations adopted by apposed cell populations (Fig. 3) offer evidence on this matter.

\section{Malignant invasion and tissue miscibility: are they re- lated?}

Is cancer invasion a process of cell sorting in reverse? Cellular compartmentalization is an essential feature of organogenesis. The prostate gland for example, is composed of two distinct compartments, epithelial and stromal. Epithelial-stromal interactions are an essential feature of normal morphogenesis and cytodifferentiation of the prostate gland (Chung and Davies, 1996). The epithelial component is clearly separated from the stroma by a sharp boundary, an ECM-rich basal lamina. The stroma is composed largely of smooth muscle cells, myofibroblasts, fibroblasts, endothelial cells, inflammatory cells, as well as neuroendocrine and neurovascular components (Lopaczynski et al., 2001). This cellular compartmentalization is often lost as tumors become invasive. This is evident in prostate cancer when one compares the histology of normal glands with the histopathology of low-grade and high-grade tumors. The normal prostate is composed of large, well-defined glands distributed in a branching pattern and surrounded by an organized stroma (Fig. 7A). Low-grade prostate cancer (Gleason grade 3 ) is characterized by the presence of numerous small glands that tend to become crowded within a reduced stromal element. The glands maintain their organization and remain separated from the stroma by an intact basal lamina

Fig. 9. Interplay between cell-cell cohesivity and cell-substratum adhesivity. Small, fluorescence-labeled cellaggregates of low, intermediate and high cohesivity (top to bottom), expressing either $\mathrm{N}$-cadherin or R-cadherin, were allowed to spread for $24 \mathrm{~h}$ on a polymeric substratum of moderate adhesivity to these cells. The least cohesive aggregates $(\sigma=1.9$ dyne/cm) spread very well on this substratum but the most cohesive aggregates $(\sigma=8.7$ dyne/cm) hardly spread at all. Scale bar, 100 um. Modified after Ryan et al. (2001).

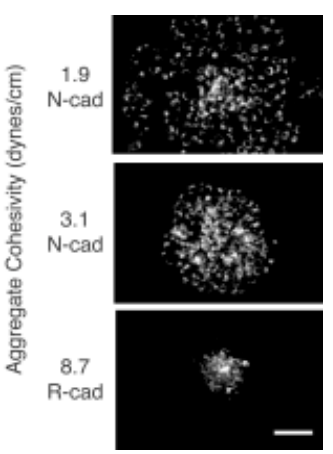

(Fig. 7B). In contrast, high-grade prostate tumors (Gleason grade 5) lose their histotypic organization. Glands are no longer apparent and tumor cells become in effect miscible with the prostatic stroma and freely intermix (Fig. 7C). Two of the theoretical configurations shown in Fig. 3 have been generated by mixing prostate cancer cells of different invasive properties with normal fibroblasts. AT-2 cells are of low metastatic potential, whereas MAT-LyLu (MLL) cells are highly metastatic to rat lymph nodes and lungs (Lubaroff et al., 1980). AT-2 and MLL cells were labeled with the red fluorescent membrane-intercalating dye PKH-26 (Sigma, MO). A normal rat fibroblast cell line (Rat 2) was stained with the green fluorescent dye PKH-2 (Sigma, MO). Either AT-2 or MLL cells were mixed 50:50 with Rat-2 cells and placed in hanging drop cultures for 48 hours. The resulting geometries were analyzed by confocal microscopy. As can be seen in Fig. 8, AT-2 cells appear to have a lower affinity for Rat 2 cells than did the MLL. This is evident since the resultant geometry of the AT-2/Rat 2 combination gave rise to a sphere within a sphere configuration as depicted in Case B of Fig. 3. In contrast, MLL cells remained intermixed with the Rat 2 fibroblasts, indicating a high degree of cross-affinity, as depicted in Case A of Fig. 3. This result is consistent with the idea that more aggressive cancer cells would likely require an ability to interact with fibroblasts, a major component of the stroma in prostate cancer (Chang and Chung, 1989; Chung, 1991; Chung and Davies, 1996). Thus, the progression of prostate cancer from a manageable organ-confined status to a clinically intractable metastatic disease may be in effect due to a process of reverse cell sorting in which distinct compartments between tumor and stromal cells are lost.

\section{Cadherins and malignant invasion}

E-, N-, P-, T- and VE-cadherin have all been linked with transition to malignancy of a variety of tumors. Most notably, Ecadherin has been implicated as being an important molecule in invasion and metastasis largely because its expression is in some cases inversely correlated with tumor aggressiveness. Malignancy-associated parameters such as loss of differentiation, invasiveness and metastatic potential of a broad range of carcinomas are often associated with down-regulation of E-cadherin expression or function (Mareel etal., 1997, Mareel etal., 1992). Moreover, antagonizing constitutive E-cadherin activity by function-inhibiting antibodies has produced a more invasive phenotype in MDCK cells (Behrens et al., 1989), whereas transfection of E-cadherin cDNA into invasive cells deficient in E-cadherin has inhibited their invasion (Chen and Obrink 1991, Frixen et al., 1991). These and other studies have led to the characterization of the E-cadherin gene as a tumor (invasion) suppressor gene (Vleminckx et al., 1991). Reduced or absent E-cadherin expression is considered a hallmark of malignancy in a variety of cancers including breast (Berx and Van Roy 2001), lung (Bremnes et al., 2002), skin (McGary et al., 2002), pancreas (Joo etal., 2002b), cervical (Chen etal., 2003), endometrial (Saito etal., 2003), nasopharyngeal (Tsao etal., 2003) and gastric cancers (Joo et al., 2002a).

A review of the literature indicates that down-regulation of cadherin expression, however, is not always predictive of invasiveness. This is likely due to the fact that expression of an adhesion protein such as E-cadherin does not necessarily reflect its function. There are many examples in which highly invasive cell lines 
express normal levels of E-cadherin but exhibit abnormalities in the expression or function of their cytoplasmic catenins or in the ability of E-cadherin to form strong, stable bonds. Inappropriate regulation of cadherin expression levels or functionality has been observed in many human malignancies. For comprehensive reviews see (Cairns et al., 2003, Choong 2003, Mareel and Leroy 2003, Nollet et al., 2000).

\section{Regulation of cadherin function}

Cadherins play an important role in specific cell-cell adhesion events. Their expression appears to be tightly regulated during development. Several mechanisms have been demonstrated to act in the regulation of cadherin function. For example, changes in the composition of the cadherin/catenin complex are thought to alter binding activity of cadherins. Down-regulation of $\alpha$-catenin results in alterations in the interaction of the complex with the actin cytoskeleton, resulting in decreased cadherin activity (Imamura et al., 1999, Nagafuchi et al., 1991). Altered cell adhesion has been reported also to be associated with disruption of $\alpha$-catenin $/ \beta$ catenin binding. Tyrosine phosphorylation of $\beta$-catenin is thought to be responsible for this effect (Ozawa and Kemler 1998). In some cell lines, the protein p120ctn, acts as an inhibitor of cadherinmediated adhesion, because either deletion of the juxtamembrane domain or introduction of mutant p120ctn reactivates cadherin function (Aono et al., 1999). Tyrosine phosphorylation of the cadherin/catenin complex has also been implicated in the regulation of adhesion (Daniel and Reynolds 1997, Roura et al., 1999). Both receptor tyrosine kinases and receptor tyrosine phosphatases have been found to immunoprecipitate with catenin-cadherin complexes (Brady-Kalnay et al., 1995, Hoschuetzky et al., 1994). Moreover, kinase inhibitors, such as staurosporine, have been shown to reactivate cohesion in cell lines (Aono et al., 1999). The small GTPases, Rac, Rho and Cdc42, have also been implicated in cadherin-mediated adhesion (Fukata etal., 1999, Kaibuchi etal., 1999). Over-expression of constitutively active Rac generally results in increased cadherin activity, whereas expression of dominant-negative Rac has the opposite effect (Braga etal., 1997). Lateral dimerization of cadherins also seems to be required for proper adhesive function (Tamura et al., 1998). More recently, Hellberg et al., have shown that protein tyrosine phosphatase (PTP) regulates the protein kinase $\mathrm{C}(\mathrm{PKC})$ pathway to restore $\mathrm{E}$ cadherin-dependent cell adhesion via its' interaction with Rac-1 in human prostate carcinoma cells (Hellberg et al., 2002). Tumorassociated hypermethylation of the E-cadherin gene can also regulate function (Chen et al., 2003, Di Croce and Pelicci 2003, Saito et al., 2003, Tsao et al., 2003). E-cadherin expression and function were restored by treatment with 5-azacytidine, a demethylating agent (Mareel and Leroy 2003). E-cadherin function can also be restored by treatment with the Ras farnesylation inhibitor FTI-277. In cell aggregation assays, FTI-277 stimulated aggregation of colon, liver and breast cancer cells. Immunoblotting analysis showed that FTI-277 increased E-cadherin/catenin expression and strongly stabilized the interaction of E-cadherin/ catenin with the actin cytoskeleton. In vivo, selective inhibition of Ras activation by FTI-277 treatment markedly reduced splenic primary tumor growth and the rate of liver metastasis compared with controls (Nam et al., 2002a). Selective inhibition of Src activation had similar effects (Nam et al., 2002b). Given the complex molecular milieu required for the initiation and maturation of strong cadherin-based intercellular cohesion, the best measure of cadherin function is not expression of the protein but rather the intercellular adhesive energy.

\section{What is the basis for cadherin function in tumor inva- sion-suppression?}

Tumors are complex tissues whose component cells are held together by forces generated both by cell-cell and cell-ECM interactions. For invasion to occur, invading cells must acquire the ability to detach from the main tumor mass. Invading cells must also possess some degree of affinity for the stroma in which they reside. Thus, malignant invasion may be viewed as a "tug of war" between two opposing forces: cell-cell cohesion maintaining immiscibility of tumor cells and surrounding tissues and cell-substratum adhesion, promoting the miscibility of tumor cells with their surroundings. Any shift in the balance between these two forces could, in principle, strongly influence invasiveness. We long ago pointed out that the spreading of a multilayered tissue mass over a substratum should be regulated by the balance of cell-cell vs. cell-substratum binding energies (Martz etal., 1974). Recently this was empirically demonstrated by comparing the spreading behavior of cell aggregates having different levels of cadherin-mediated cohesivity on a series of copolymeric substrata having different levels of cell-substratum adhesivity. It was shown that either decreasing cell-substratum adhesivity or increasing cell-cell cohesivity dramatically slowed the spreading rate of cell aggregates (Fig. 9) (modified after (Ryan et al., 2001).

As has already been noted, loss of epithelial E-cadherin expression or function through down-regulation or mutation, abnormality

Fig. 10. N-cadherin mediated inhibition of HeLa cell spreading on Matrigel. HeLa cell aggregates were placed in Matrigel-coated wells and incubated at $37^{\circ} \mathrm{C}$ for 4 hours. (A) Untransfected HLTO cells spread readily on the reconstituted ECM. (B) The $\mathrm{N}$-cadherin transfected line HLTO (tet-off) N5.5 also spreads readily if
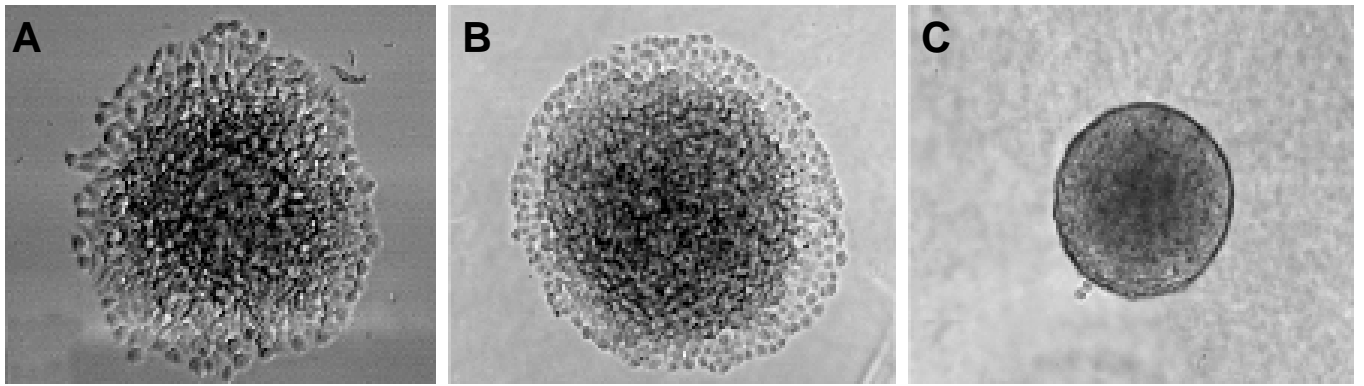

cadherin expression is not induced $(+5 \mathrm{ng} / \mathrm{ml}$ doxycycline (dox). (C) When the HLTO N5.5 cells are induced to express N-cadherin (no dox), the cell line loses its propensity to spread. Images were collected by phase contrast microscopy using a10X objective. From Duguay (2000). 
or deletion of the catenins or biochemical alteration such as phosphorylation of $\beta$-catenin (Shiozaki et al., 1996) has a high correlation with invasive potential; and invasive cell lines can often be rendered non-invasive by transfecting them with the $E$-cadherin gene. Like the other members of the cadherin superfamily, Ecadherin has important biological functions in addition to its role in cell-cell adhesion. E-cadherin may be part of a signal transduction pathway leading to the transcription of certain genes, which could be the true suppressors of invasion. Alternatively, E-cadherin could function directly by increasing the cohesivity of the cells, physically restraining them from emigrating from the tumor mass. In that case, any other cell adhesion molecule that could produce a similar level of cohesion should suppress invasion to the same extent. To distinguish between these two alternatives, we transfected the highly invasive Lewis lung carcinoma (LLC) cell line with cDNA encoding the expression of either $\mathrm{E}$ - or $\mathrm{P}$-cadherin. We then produced aggregates from these cell lines and measured their cohesivity by tissue surface tensiometry. We also performed invasion assays on Matrigel which consists of reconstituted extracellular matrix. When, by E-cadherin-mediated transfection, we increased the cohesivity of the parent line by as little as $46 \%$, this cell line's invasive behavior in vitro was almost completely eliminated. To determine whether the above suppression of invasiveness is specific to E-cadherin or might be a property shared with other cadherins, we first transfected LLC cells to express Pcadherin at levels equal to those expressed by the E-cadherin transfectants. We showed that $\mathrm{P}$-cadherin is equally effective at suppression of invasion through Matrigel, suggesting that suppression of this invasion simply requires a generic increase in cohesivity as opposed to a cadherin subtype-specific event. We also found that transfilter invasion through Matrigel of sparsely plated cells, unlike that of aggregates, was unaffected by cadherin expression, indicating that suppression of invasiveness by cadherins requires cell-cell contact (Foty and Steinberg 1997).

Similar results have been obtained with $\mathrm{N}$-cadherin-transfected HeLa cells, whose ability to spread on Matrigel was examined as a function of $\mathrm{N}$-cadherin expression, varied through use of an inducible promoter. Aggregates of the parental HeLa cell line spread readily on Matrigel. Transfected but uninduced HeLa cell aggregates also spread readily on it. Only cells that have been transfected and induced to express $\mathrm{N}$-cadherin are prevented from spreading on the matrix (Fig. 10) (Duguay 2000). These findings rule out the possibility that E-cadherin-mediated suppression of invasion is the result of a signaling pathway specific to E-cadherin. It must be due to a property that is shared with at least $\mathrm{N}$ - and $\mathrm{P}$-cadherin and quite probably other cadherins as well. This could involve a signaling pathway common to multiple cadherins, or alternatively it could be due to the increased cohesiveness of cells when they are expressing one of these cadherins. Since all three of these cadherins can prevent the spreading of malignant cell populations over ECM, it may be possible to suppress the invasion of tumor cells by increasing their cohesiveness through these or other means.

\section{Breast cancer}

The correlation between cadherin expression and malignancy is strong in breast cancer where partial or complete loss of Ecadherin expression has been found to directly influence tumor histology (Moll et al., 1993). E-cadherin gene expression profiling by cDNA microarray has also demonstrated a marked difference between ductal and lobular forms of breast cancer (Korkola et al., 2003). Ductal breast cancers in general show heterogeneous loss of E-cadherin expression, associated with epigenetic transcriptional down-regulation (Berx and Van Roy 2001). The genetic mechanisms underlying differential E-cadherin expression in invasive lobular breast cancer have been attributed to both inactivating mutations and loss of heterozygosity of the wild-type $\mathrm{CDH} 1$ allele. Whereas there appears to be a strong correlation between downregulation of $\mathrm{E}$-cadherin expression and malignancy in breast cancer, this relationship is less clear in other types of cancers including prostate and brain.

\section{Prostate cancer}

The degree of E-cadherin expression in prostate cancer remains controversial. Some studies have reported decreased expression of E-cadherin as tumors advance and metastasize. Other studies have not demonstrated this relationship. To address these variations, Rubin et al. (2001) undertook a study to systematically evaluate E-cadherin expression in a broad range of prostate tissue using a broad-spectrum high density tissue micro-array (TMA) study in which 1,220 prostate TMA samples were analyzed for expression of E-cadherin. Benign prostate, clinically localized prostate cancer and hormone-refractory metastatic prostate cancer were analyzed under uniform conditions using an excellent commercially available antibody (HECD-1). High (normal) Ecadherin expression was seen in $87 \%$ of 757 benign, $80 \%$ of 41 high-grade PIN, $82 \%$ of 325 prostate carcinoma and $90 \%$ of 97 hormone-refractory prostate carcinoma TMA samples. Thus, in metastatic hormone-refractory prostate tumors, E-cadherin was uniformly expressed and only in rare cases was aberrant expression detected (Rubin et al., 2001). Another large study using an antigen retrieval protocol examined 2,378 biopsy cores from 289 prostates. E-cadherin was found to be a poor marker, as it was expressed in all lesions except Gleason 5 carcinomas (Slater et al., 2003). Such data bring into question the broad-based application of E-cadherin expression as a universal prognostic factor for invasive potential of prostate cancer.

\section{Brain cancer}

Cadherin expression in brain tumors has also been shown to be variable. E-cadherin expression was studied in 145 human brain tumors including astrocytomas and meningiomas. E-cadherin was expressed by benign meningiomas but also by meningiomas invading dura, bone, brain and muscle (Schwechheimer et al., 1998). The expression of $\mathrm{N}$-cadherin, the predominant cadherin in neural tissues, was examined in a series of gliomas and glioblastoma cell lines. Surprisingly, $\mathrm{N}$-cadherin levels were significantly higher in glioblastomas than in low-grade astrocytomas. Moreover, tumor invasiveness did not correlate with $\mathrm{N}$-cadherin expression in tumors within the same histopathological grade (Shinoura et al., 1995). These data suggest that, unlike E-cadherin in carcinomas, $\mathrm{N}$-cadherin does not restrict the invasion of glioblastoma cells but may even enhance invasiveness. Indeed, down regulation of $\mathrm{E}$ cadherin is often accompanied by increased $\mathrm{N}$-cadherin expression, suggesting that $\mathrm{N}$-cadherin, rather than promoting intercellular cohesion, may instead promote emigration of cells from a tumor. Interestingly, transfecting the weakly metastatic and E-cadherinexpressing breast cancer cell line MCF-7 with $\mathrm{N}$-cadherin con- 
verted MCF-7 cells into highly motile and invasive cells. In vivo, Ncadherin-expressing MCF-7 cells metastasized to the liver, pancreas, salivary gland, omentum, lung, lymph nodes and lumbar spinal muscle (Hazan et al., 2000). $\mathrm{N}$-cadherin is expressed by stromal cells such as myofibroblasts, neurons, smooth muscle cells and endothelial cells (De Wever and Mareel 2003). The shift from $\mathrm{E}$ - to $\mathrm{N}$-cadherin expression could, in principle, promote tumor cell-stromal cell association.

\section{An integrin can mediate strong cell-cell adhesions}

Adhesion molecules on closely apposed surfaces interact either directly, as is the case with cadherins, or indirectly through integrinECM interaction. Our previous studies of cell aggregate surface tensions, discussed above, have measured the intercellular binding energies produced by direct, cadherin-mediated intercellular cohesions. Recently, we have used tissue surface tensiometry to measure the binding energies among cells whose adhesions are mediated via $\alpha 5 \beta 1$-integrin and FN. We showed that in 3D cellular aggregates, integrin, acting through fibronectin, can mediate stronger aggregate cohesivity than a typical cadherin-cadherin interaction (Robinson et al., 2003) and that this cohesivity is dependent upon the presence of a fibrillar FN matrix (Robinson et al., 2004). Over-expression of various integrins has been associated with increased potential for invasion and migration. $\alpha 5 \beta 1$ integrin, however, is often down-regulated in metastatic cancer and overexpression has been shown to rescue a transformed phenotype (Giancotti and Ruoslahti 1990). Our recent observations suggest a possible role for $\alpha 5 \beta 1$ integrin as an invasion suppressor molecule, much as has been reported for E-cadherin. If $\alpha 5 \beta 1-F N$ interaction is indeed capable of conferring cohesivity upon tissues, particularly very early in development, then it is possible that $\alpha 5 \beta 1$ integrin-FN interactions may also have the capacity to contribute to the cohesivity of cells within the gastrula. Injection of RGD peptide into amphibian blastulae blocks gastrulation by disrupting cell interactions with FN and preventing formation of the meshwork of FN fibrils involved in mesoderm migration (Boucaut et al., 1984). Indeed, Davis et al., have shown that the cohesivities of the germ layers in amphibian gastrulae correlate perfectly with their spatial positions (Davis et al., 1997). FN-mediated compaction has also been shown to be important later in development. When aggregates of embryonic chick heart ventricle tissue were paired in organ culture, aggregates that developed a fibronectin-rich matrix were rapidly spread upon by aggregates that were less able to deposit fibronectin in the matrix (Armstrong and Armstrong 1984). Downie and Newman demonstrated that a correlation exists between FN secretion and pre-cartilage mesenchymal condensation during wing and leg bud development in chick embryos (Downie and Newman 1995), with high FN secretion correlating with compact and spheroidal condensation. The $\alpha 5 \beta 1$ integrin-FN interaction has also been shown to be vital for retraction of 3-D FN-fibrin clot matrices (Corbett and Schwarzbauer 1999), a process crucial to early wound healing and tissue remodeling. Recent studies of cadherin-integrin cross-talk have shown that $\alpha_{v}$ integrin-dependent adhesion suppresses E-cadherin-mediated spheroid formation by breast cancer cells and that conversely, introduction of a dominant-negative E-cadherin mutant results not only in loss of intercellular cohesion but also in increased migration towards ECM (von Schlippe et al., 2000). This provides yet another mechanism whereby molecular mediators of tissue cohesivity may be influ- enced through several molecular pathways. Another example includes recent studies demonstrating that $\mathrm{N}$-cadherin and $\beta$ integrins are coordinately regulated by dissociation of the nonreceptor tyrosine kinase Ferfrom $\mathrm{N}$-cadherin and its subsequent association with the integrin complex (Arregui et al., 2000). This coordinated transposition of an effector molecule such as Ferfrom cadherins to integrins provides a mechanism for rapid, specific and coordinate regulation of cell-cell and cell-substratum adhesion and could, in principle, alter cadherin and integrin-based tissue cohesivity and cell sorting behavior. Matrix metalloproteinases (MMPs) are believed to play a pivotal role in malignant behavior of cancer cells such as rapid tumor growth, invasion and metastasis by degrading extracellular matrix (ECM). MMP-7 (matrilysin) not only has the capacity to degrade fibronectin (Wilson and Matrisian 1996), but has also been shown to cleave E-cadherin (Noe et al., 2001). Thus, in 3D aggregates, metalloproteinases have the capacity to influence intercellular cohesion directly through cadherins and also indirectly by disrupting integrin-ECM interaction.

\section{Summary}

Embryonic tissue segregation represents a powerful anatomygenerating event and reflects an interplay between genetic information, the molecular machinery it encodes and principles of physics, as cell groups rearrange to adopt specific relationships. The establishment and maintenance of compartments and boundaries between cell populations represents an immiscibility phenomenon. Whether cell populations segregate or intermix depends largely on the actual function rather than merely the expression of cell-cell and cell-matrix adhesion molecules whose intercellular binding energies can be harnessed to direct the segregation process. In contrast, the intrusion of tumor cells into surrounding tissue results in the intermixing of tumor cells with the stroma in which they reside and is considered to be a hallmark of malignancy. Interestingly, the very same molecules giving rise to tissue compartmentalization during morphogenesis are involved in the elimination of these boundaries during invasion and metastasis. Accordingly, understanding cellular processes underlying malignant invasion will benefit from an approach rooted in the same thermodynamic principles governing boundary formation. Such an approach would focus on differential tissue cohesive and adhesive relationships and would de-emphasize the contribution of any single adhesion system in mediating tumor behavior.

\section{References}

ADAMS, C. L., NELSON, W. J., and SMITH, S. J. (1996). Quantitative analysis of cadherin-catenin-actin reorganization during development of cell-cell adhesion. $J$. Cell Biol. 135: 1899-911.

ALAHARI, S. K., REDDIG, P. J., and JULIANO, R. L. (2002). Biological aspects of signal transduction by cell adhesion receptors. Int Rev Cyto/220: 145-84.

ANGRES, B., BARTH, A., and NELSON, W. J. (1996). Mechanism for transition from initial to stable cell-cell adhesion: kinetic analysis of E-cadherin-mediated adhesion using a quantitative adhesion assay. J. Cell Biol. 134: 549-557.

AONO, S., NAKAGAWA, S., REYNOLDS, A. B., and TAKEICHI, M. (1999). p120(ctn) acts as an inhibitory regulator of cadherin function in colon carcinoma cells. $J$ Cell Biol145: 551-62.

ARMSTRONG, P. B., and ARMSTRONG, M. T. (1984). A role for fibronectin in cell sorting. J Cell Sci69: 179-97.

ARMSTRONG, P. B., and PARENTI, D. (1972). Cell sorting in the presence of cytochalasin B. J. Cell Biol. 55: 542-553. 
ARREGUI, C., PATHRE, P., LILIEN, J., and BALSAMO, J. (2000). The nonreceptor tyrosine kinase fer mediates cross-talk between $\mathrm{N}$-cadherin and beta1-integrins. $J$ Cell Bio/149: 1263-74.

BEHRENS, J., MAREEL, M. M., VAN ROY, F. M., and BIRCHMEIER, W. (1989). Dissecting tumor cell invasion: epithelial cells acquire invasive properties after the loss of uvomorulin-mediated cell-cell adhesion. J Cel/ Bio/108: 2435-47.

BERX, G., and VAN ROY, F. (2001). The E-cadherin/catenin complex: an important gatekeeper in breast cancer tumorigenesis and malignant progression. Breast Cancer Res 3: 289-93.

BOGENRIEDER, T., and HERLYN, M. (2003). Axis of evil: molecular mechanisms of cancer metastasis. Oncogene 22: 6524-36.

BOUCAUT, J. C., DARRIBERE, T., POOLE, T. J., AOYAMA, H., YAMADA, K. M., and THIERY, J. P. (1984). Biologically active synthetic peptides as probes of embryonic development: a competitive peptide inhibitor of fibronectin function inhibits gastrulation in amphibian embryos and neural crest cell migration in avian embryos. JCell Bio/99: 1822-30.

BRADY-KALNAY, S. M., RIMM, D. L., and TONKS, N. K. (1995). Receptor protein tyrosine phosphatase PTPmu associates with cadherins and catenins in vivo. $\mathrm{JCe} / \mathrm{J}$ Biol130: 977-86.

BRAGA, V. M., MACHESKY, L. M., HALL, A., and HOTCHIN, N. A. (1997). The small GTPases Rho and Rac are required for the establishment of cadherin-dependent cell-cell contacts. J Cel/ Bio/137: 1421-31.

BREMNES, R. M., VEVE, R., HIRSCH, F. R., and FRANKLIN, W. A. (2002). The Ecadherin cell-cell adhesion complex and lung cancer invasion, metastasis, and prognosis. Lung Cancer36: 115-24.

BRODLAND, G. (2002). The differential interfacial tension hypothesis (DITH): a comprehensive theory for the self-rearrangement of embryonic cells and tissues. $J$. Biomech. Engineer. 124: 188-197.

CAIRNS, R. A., KHOKHA, R., and HILL, R. P. (2003). Molecular mechanisms of tumor invasion and metastasis: an integrated view. Curr Mol Med 3: 659-71.

CHANG, S. M., AND CHUNG, L. W. (1989). Interaction between prostatic fibroblast and epithelial cells in culture: role of androgen. Endocrinology 125, 2719-27.

CHEN, C. L., LIU, S. S., IP, S. M., WONG, L. C., NG, T. Y., and NGAN, H. Y. (2003). E-cadherin expression is silenced by DNA methylation in cervical cancer cell lines and tumours. Eur J Cancer39: 517-23.

CHEN, W. C., and OBRINK, B. (1991). Cell-cell contacts mediated by E-cadherin (uvomorulin) restrict invasive behavior of L-cells. J Cell Bio/114: 319-27.

CHOONG, P. F. (2003). The molecular basis of skeletal metastases. Clin Orthop. S19-31.

CHUNG, L. W. (1991). Fibroblasts are critical determinants in prostatic cancer growth and dissemination. Cancer Metastasis Rev10, 263-74.

CHUNG, L. W., AND DAVIES, R. (1996). Prostate epithelial differentiation is dictated by its surrounding stroma. Mol Biol Rep23, 13-9.

CORBETT, S. A., and SCHWARZBAUER, J. E. (1999). Requirements for alpha(5)beta(1) integrin-mediated retraction of fibronectin-fibrin matrices. $J$ Biol Chem 274: 20943-8.

DANIEL, J. M., and REYNOLDS, A. B. (1997). Tyrosine phosphorylation and cadherin/ catenin function. Bioessays 19: 883-91.

DAVIES, J., and RIDEAL, E. (1961). Interfacial Phenomena. Academic Press, New York.

DAVIS, G. 1984. Migration-directing liquid properties of embryonic amphibian tissues. Amer. Zool. 24: 649-655.

DAVIS, G., PHILLIPS, H., and STEINBERG, M. (1997). Germ-layer surface tensions and «tissue affinities» in Rana pipiens gastrulae: quantitative measurements. Dev. Biol. 192: 630-644.

DE WEVER, O., and MAREEL, M. (2003). Role of tissue stroma in cancer cell invasion. $J$ Patho/200: 429-47.

DI CROCE, L., and PELICCI, P. G. (2003). Tumour-associated hypermethylation: silencing E-cadherin expression enhances invasion and metastasis. Eur J Cancer 39: 413-4.

DOWNIE, S. A., and NEWMAN, S. A. (1995). Different roles for fibronectin in the generation of fore and hind limb precartilage condensations. Dev Bio/172: 519-30.

DUGUAY, D. (2000). Cross adhesion between different cadherins and the basis for cadherin function in tumor invasion-suppression. Ph.D. thesis. 117 pp. Department of Molecular Biology. Princeton University, Princeton.

DUGUAY, D., FOTY, R., and STEINBERG, M. (2003). Cadherin-mediated cell adhesion and tissue segregation: qualitative and quantitative determinants. Dev. Biol. 253: $309-323$
FOTY, R., FORGACS, G., PFLEGER, C., and STEINBERG, M. (1994). Liquid properties of embryonic tissues: Measurement of interfacial tensions. Phys. Rev. Lett. 72: 2298-2301.

FOTY, R. A., PFLEGER, C. M., FORGACS, G., and STEINBERG, M. S. (1996). Surface tensions of embryonic tissues predict their mutual envelopment behavior. Development 122: 1611-20.

FOTY, R. A., and STEINBERG, M. S. (1997). Measurement of tumor cell cohesion and suppression of invasion by E- or P-cadherin. Cancer Res 57: 5033-6.

FRIXEN, U. H., BEHRENS, J., SACHS, M., EBERLE, G., VOSS, B., WARDA, A., LOCHNER, D., and BIRCHMEIER, W. (1991). E-cadherin-mediated cell-cell adhesion prevents invasiveness of human carcinoma cells. J Cel/ Bio/113: 173-85.

FUKATA, M., NAKAGAWA, M., KURODA, S., and KAIBUCHI, K. (1999). Cell adhesion and Rho small GTPases. J Cell Sci112: 4491-500.

GIANCOTTI, F. G., and RUOSLAHTI, E. (1990). Elevated levels of the alpha 5 beta 1 fibronectin receptor suppress the transformed phenotype of Chinese hamster ovary cells. Ce//60: 849-59.

HARRIS, A. (1975). Is cell sorting caused by differences in the work of intercellular adhesion? A critique of the Steinberg Hypothesis. J. Theor. Biol. 61: 267-285.

HAZAN, R. B., PHILLIPS, G. R., QIAO, R. F., NORTON, L., and AARONSON, S. A. (2000). Exogenous expression of $\mathrm{N}$-cadherin in breast cancer cells induces cell migration, invasion, and metastasis. J Cell Bio/148: 779-90.

HELLBERG, C. B., BURDEN-GULLEY, S. M., PIETZ, G. E., and BRADY-KALNAY, S. M. (2002). Expression of the receptor protein tyrosine phosphatase, PTPmu, restores E-cadherin-dependent adhesion in human prostate carcinoma cells. J Biol Chem 18: 18.

HOLTFRETER, J. (1939). Gewebeaffinität, ein Mittel der embryonal Formbildung. Arch. Exptl. Zellforsch. Gewebezucht. 23: 169-209.

HOSCHUETZKY, H., ABERLE, H., and KEMLER, R. (1994). Beta-catenin mediates the interaction of the cadherin-catenin complex with epidermal growth factor receptor. J Cel/ Bio/127: 1375-80.

IMAMURA, Y., ITOH, M., MAENO, Y., TSUKITA, S., and NAGAFUCHI, A. (1999). Functional domains of alpha-catenin required for the strong state of cadherin-based cell adhesion. J Cell Bio/144: 1311-22

JOO, Y. E., REW, J. S., CHOI, S. K., BOM, H. S., PARK, C. S., and KIM, S. J. (2002a) Expression of E-cadherin and catenins in early gastric cancer. JClin Gastroenterol 35: 35-42.

JOO, Y. E., REW, J. S., PARK, C. S., and KIM, S. J. (2002b). Expression of E-cadherin, alpha-and beta-catenins in patients with pancreatic adenocarcinoma. Pancreatology 2: $129-37$.

KAIBUCHI, K., KURODA, S., FUKATA, M., and NAKAGAWA, M. (1999). Regulation of cadherin-mediated cell-cell adhesion by the Rho family GTPases. Curr Opin Cell Biol11: 591-6.

KORKOLA, J. E., DEVRIES, S., FRIDLYAND, J., HWANG, E. S., ESTEP, A. L., CHEN Y. Y., CHEW, K. L., DAIRKEE, S. H., JENSEN, R. M., and WALDMAN, F. M. (2003). Differentiation of lobular versus ductal breast carcinomas by expression microarray analysis. Cancer Res 63: 7167-75.

LOPACZYNSKI, W., HRUSZKEWYCZ, A. M., AND LIEBERMAN, R. (2001) Preprostatectomy: A clinical model to study stromal-epithelial interactions. Urology 57, 194-9.

LUBAROFF, D. M., CANFIELD, L., AND REYNOLDS, C. W. (1980). The Dunning tumors. Prog Clin Biol Res 37, 243-63.

MAREEL, M., and LEROY, A. (2003). Clinical, cellular, and molecular aspects of cancer invasion. Physiol Rev83: 337-76.

MAREEL, M., VERMEULEN, S., and BRACKE, M. (1997). Molecular mechanism of cancer seeding: adhesion molecules and signal transduction networks. Verh $K$ Acad Geneeskd Belg 59: 327-51.

MAREEL, M., VLEMINCKX, K., VERMEULEN, S., BRACKE, M., and VAN ROY, F. (1992). E-cadherin expression: a counterbalance for cancer cell invasion. Bull Cancer 79: 347-55

MARTZ, E., PHILLIPS, H. M., and STEINBERG, M. S. (1974). Contact inhibitions of overlapping and differential cell adhesion: a sufficient model for the control of certain cell culture morphologies. J Cel/ Sci16: 401-19.

MCGARY, E. C., LEV, D. C., and BAR-ELI, M. (2002). Cellular adhesion pathways and metastatic potential of human melanoma. Cancer Biol Ther 1: 459-65.

MOLL, R., MITZE, M., FRIXEN, U. H., and BIRCHMEIER, W. (1993). Differential loss of E-cadherin expression in infiltrating ductal and lobular breast carcinomas. $A m J$ Pathol143: 1731-42. 
MOYER, W., and STEINBERG, M. (1976). Do rates of intercellular adhesion measure the cell affinities reflected in cell-sorting and tissue-spreading configurations? Developmental Biology 52: 246-262.

NAGAFUCHI, A., TAKEICHI, M., and TSUKITA, S. (1991). The 102 kd cadherinassociated protein: similarity to vinculin and posttranscriptional regulation of expression. Cel/65: 849-57.

NAM, J. S., INO, Y., SAKAMOTO, M., and HIROHASHI, S. (2002a). Ras farnesylation inhibitor FTI-277 restores the E-cadherin/catenin cell adhesion system in human cancer cells and reduces cancer metastasis. Jpn J Cancer Res 93: 1020-8.

NAM, J. S., INO, Y., SAKAMOTO, M., and HIROHASHI, S. (2002b). Src family kinase inhibitor PP2 restores the E-cadherin/catenin cell adhesion system in human cancer cells and reduces cancer metastasis. Clin Cancer Res 8: 2430-6.

NOE, V., FINGLETON, B., JACOBS, K., CRAWFORD, H. C., VERMEULEN, S., STEELANT, W., BRUYNEEL, E., MATRISIAN, L. M., and MAREEL, M. (2001). Release of an invasion promoter E-cadherin fragment by matrilysin and stromelysin1. J Cell Sci114: 111-118.

NOLLET, F., KOOLS, P., and VAN ROY, F. (2000). Phylogenetic analysis of the cadherin superfamily allows identification of six major subfamilies besides several solitary members. JMo/ Bio/299: 551-72.

NOSE, A., NAGAFUCHI, A., and TAKEICHI, M. (1988). Expressed recombinant cadherins mediate cell sorting in model systems. Cel/54: 993-1001.

OZAWA, M., and KEMLER, R. (1998). Altered cell adhesion activity by pervanadate due to the dissociation of alpha-catenin from the E-cadherin.catenin complex. J Biol Chem 273: 6166-70.

PEREZ-MORENO, M., JAMORA, C., and FUCHS, E. (2003). Sticky business: orchestrating cellular signals at adherens junctions. Cel/112: 535-48.

PHILLIPS, H. M. (1969). Equilibrium measurements of embryonic cell adhesiveness. physical formulation and testing of the differential adhesion hypothesis. Ph.D. Thesis. 236 pp. Dept. of Biology. The Johns Hopkins University, Baltimore.

PHILLIPS, H. M., and DAVIS, G. S. (1978). Liquid-tissue mechanics in amphibian gastrulation: germ layer assembly in Rana pipiens. Amer. Zool. 18: 81-93.

PHILLIPS, H. M., and STEINBERG, M. S. (1969). Equilibrium measurements of embryonic chick cell adhesiveness: I. Shape equilibrium in centrifugal fields. Proc. Natl Acad. Sci. USA 64: 121-127.

ROBINSON, E. E., FOTY, R. A., and CORBETT, S. A. (2004). Fibronectin matrix assembly regulates alpha5beta1-mediated cell cohesion. Mol Biol Cel/12: 12

ROBINSON, E. E., ZAZZALI, K. M., CORBETT, S. A., and FOTY, R. A. (2003). alpha5beta1 integrin mediates strong tissue cohesion. J Cell Sci116: 377-86.

ROTH, S. A. (1968). Studies on intercellular adhesive selectivity. Dev. Biol. 18:602-631.

ROTH, S. A., and WESTON, J. A. (1967). The measurement of intercellular adhesion. Proc. Natl. Acad. Sci. USA 58: 974-980.

ROURA, S., MIRAVET, S., PIEDRA, J., GARCIA DE HERREROS, A., and DUNACH, M. (1999). Regulation of E-cadherin/catenin association by tyrosine phosphorylation. J Biol Chem 274: 36734-40.

ROWLINSON, J. S., and WIDOM, B. (1989). Molecular Theory of Capillarity. Clarendon Press, Oxford.

RUBIN, M. A., MUCCI, N. R., FIGURSKI, J., FECKO, A., PIENTA, K. J., and DAY, M. L. (2001). E-cadherin expression in prostate cancer: a broad survey using highdensity tissue microarray technology. Hum Patho/32: 690-7.

RYAN, P. L., FOTY, R. A., KOHN, J., and STEINBERG, M. S. (2001). Tissue spreading on implantable substrates is a competitive outcome of cell-cell vs. cell-substratum adhesivity. Proc Nat/ Acad Sci USA 98: 4323-7.

SAITO, T., NISHIMURA, M., YAMASAKI, H., and KUDO, R. (2003). Hypermethylation in promoter region of $\mathrm{E}$-cadherin gene is associated with tumor dedifferention and myometrial invasion in endometrial carcinoma. Cancer 97: 1002-9.

SCHWECHHEIMER, K., ZHOU, L., and BIRCHMEIER, W. (1998). E-Cadherin in human brain tumours: loss of immunoreactivity in malignant meningiomas. Virchows Arch 432: 163-7.

SHINOURA, N., PARADIES, N. E., WARNICK, R. E., CHEN, H., LARSON, J. J., TEW, J. J., SIMON, M., LYNCH, R. A., KANAI, Y., HIROHASHI, S., HEMPERLY, J. J., MENON, A. G. and BRACKENBURY, R. (1995). Expression of N-cadherin and alpha-catenin in astrocytomas and glioblastomas. Br J Cancer72: 627-33.

SHIOZAKI, H., OKA, H., INOUE, M., TAMURA, S., and MONDEN, M. (1996). Ecadherin mediated adhesion system in cancer cells. Cancer Supplement 77: 1605-1613.
SLATER, M. D., LAUER, C., GIDLEY-BAIRD, A., and BARDEN, J. A. (2003). Markers for the development of early prostate cancer. J Patho/199: 368-77.

STEINBERG, M. S. (1962a). On the mechanism of tissue reconstruction by dissociated cells. I. Population kinetics, differential adhesiveness, and the absence of directed migration. Proc. Natl. Acad. Sci. USA 48: 1577-1582.

STEINBERG, M. S. (1962b). Mechanism of tissue reconstruction by dissociated cells. II. Time course of events. Science 137: 762-763.

STEINBERG, M. S. (1962c). On the mechanism of tissue reconstruction by dissociated cells. III. Free energy relations and the reorganization of fused heteronomic tissue fragments. Proc. Natl. Acad. Sci. USA 48: 1769-1776.

STEINBERG, M. S. (1963). Reconstruction of tissues by dissociated cells. Science 141 401-408.

STEINBERG, M. S. (1964). The problem of adhesive selectivity in cellular interactions. Pages 321-366 in E.M. Locke, ed. Cellular Membranes in Development. Academic Press, New York

STEINBERG, M. S. (1970). Does differential adhesion govern self-assembly processes in histogenesis? Equilibrium configurations and the emergence of a hierarchy among populations of embryonic cells. J. Exptl. Zool. 173: 395-434.

STEINBERG, M. S. (1975). Adhesion-guided multicellular assembly: a commentary upon the postulates, real and imagined, of the differential adhesion hypothesis, with special attention to computer simulations of cell sorting. J. Theor. Biol. 55: 431-443.

STEINBERG, M. S. (1978a). Cell-cell recognition in multicellular assembly: levels of specificity. Symp Soc Exp Bio/32: 25-49.

STEINBERG, M. S. (1978b). Specific cell ligands and the differential adhesion hypothesis: how do they fit together? Pages 99-129 in D. Garrod, ed. Specificity of Embryological Interactions. Chapman and Hall, London.

STEINBERG, M. S. (1996). Adhesion in development: an historical overview. Dev Biol 180: $377-88$.

STEINBERG, M. S. (1998). Goal-directedness in embryonic development. Integrative Biol. 1: 48-59.

STEINBERG, M. S. (2003). Cell adhesive interactions and tissue self-organization. In Origination of OrganismalForm: Beyond the Gene in Developmentaland Evolution ary Biology. (Eds. G. Müller and S.A. Newman). pp. 137-163 iMIT Press/Bradford Books, Cambridge, Mass.

STEINBERG, M. S., and TAKEICHI, M. (1994). Experimental specification of cell sorting, tissue spreading, and specific spatial patterning by quantitative differences in cadherin expression. Proc. Natl. Acad. Sci. USA 91: 206-9.

STEINBERG, M. S., and WISEMAN, L. L. (1972). Do morphogenetic tissue rearrangements require active cell movements? The reversible inhibition of cell sorting and tissue spreading by cytochalasin B. J. Cell. Biol. 55: 606-615.

TAKEICHI, M. (1988). The cadherins: cell-cell adhesion molecules controlling animal morphogenesis. Development 102: 639-55.

TAKEICHI, M. (1995). Morphogenetic roles of classic cadherins. Curr Opin Cel/ Bio/7 619-27.

TAMURA, K., SHAN, W. S., HENDRICKSON, W. A., COLMAN, D. R., and SHAPIRO, L. (1998). Structure-function analysis of cell adhesion by neural (N-) cadherin Neuron 20: 1153-63.

TOWNES, P. L., and HOLTFRETER, J. (1955). Directed movements and selective adhesion of embryonic amphibian cells. J. Exptl. Zool. 128: 53-120.

TSAO, S. W., LIU, Y., WANG, X., YUEN, P. W., LEUNG, S. Y., YUEN, S. T., PAN, J., NICHOLLS, J. M., CHEUNG, A. L., and WONG, Y. C. (2003). The association of Ecadherin expression and the methylation status of the E-cadherin gene in nasopharyngeal carcinoma cells. Eur J Cancer 39: 524-31.

VLEMINCKX, K., VAKAET, L., JR., MAREEL, M., FIERS, W., and VAN ROY, F. (1991). Genetic manipulation of $E$-cadherin expression by epithelial tumor cells reveals an invasion suppressor role. Cel/66: 107-19.

VON SCHLIPPE, M., MARSHALL, J. F., PERRY, P., STONE, M., ZHU, A. J., and HART, I. R. (2000. Functional interaction between E-cadherin and alphav-containing integrins in carcinoma cells. J Cell Sci113: 425-37.

WILSON, C. L., and MATRISIAN, L. M. (1996. Matrilysin: an epithelial matrix metalloproteinase with potentially novel functions. Int J Biochem Cel/ Bio/28: 12336.

YAP, A. S., and KOVACS, E. M. (2003. Direct cadherin-activated cell signaling: a view from the plasma membrane. J Cell Bio/160: 11-6. 